\title{
Career Recommendation System for High-School Seniors based on Government Standardized-Tests Results
}

\section{Un sistema de recomendación de carreras para estudiantes de último año de secundaria basado en los resultados de las pruebas estandarizadas estatales}

\author{
Miguel Ángel Correa Manrique ${ }^{(1)}$ \\ Mauricio Toro ${ }^{(2)}$ \\ Omar Becerra (3) \\ Daniel Otero ${ }^{(4)}$ \\ David Andres Romero Millan (5) \\ Rafael Mateus ${ }^{(6)}$ \\ (1) Universidad EAFIT. Mathematical Science Department. Medellín, Colombia. E-mail: \\ macorream@eafit.edu.co \\ (2)Universidad EAFIT. Mathematical Science Department. Medellín, Colombia. E-mail: \\ mtorobe@eafit.edu.co \\ (3)Universidad EAFIT. Mathematical Science Department. Medellín, Colombia. E-mail: \\ oabecerras@eafit.edu.co \\ (4)Universidad EAFIT. Mathematical Science Department. Medellín, Colombia. E-mail: \\ doterog@eafit.edu.co \\ (5)Universidad EAFIT. Mathematical Science Department. Medellín, Colombia. E-mail: \\ dromero1@eafit.edu.co \\ (6)Universidad EAFIT. Mathematical Science Department. Medellín, Colombia. E-mail: \\ rmateusc@eafit.edu.co
}

*Correspondence author: macorream@eafit.edu.co

\begin{abstract}
When it comes to choosing a career path, senior high-school students struggle to make a decision. The purpose of this research is to help such students select a career track by providing a match-based scored recommendation of academic and professional routes, promoting the development of the government-aided quality educational system by reducing the student dropout. Recommendations are based on the results of the Colombian standardized Saber 11 examination (which is similar to SAT [Scholastic Assessment Test] scores in the U.S.), and how other students with similar characteristics (demographic, socio-economic, family information) performed in their undergraduate tests and the Colombian standardized Saber Pro exam (which is similar to GRE -Graduate Record Examination- scores in the U.S.). Collected information was
\end{abstract}


bundled with their career choice and the recommendation system was developed using Machine Learning and Deep Learning techniques, ROC (Receiver operating characteristic) curve was computed for each career and found on average the AUC (Area under the ROC Curve) score was 0.86 despite the high variability between them. In addition, a business metric was built and evaluated.

Keywords: Career recommendation, education, standardized tests, machine learning, deep learning.

\section{RESUMEN}

Cuando se trata de elegir una carrera universitaria, los estudiantes de secundaria suelen tener dificultades al momento de tomar una decisión. Por ello, el propósito de esta investigación es ayudar a estos estudiantes a elegir un camino profesional brindándoles recomendaciones de carreras a estudiar, promoviendo así el desarrollo del sistema educativo de calidad, asistido por el gobierno, reduciendo la deserción estudiantil. Dichas recomendaciones se basan en los resultados obtenidos en los puntajes del examen estandarizado colombiano Saber 11 (similar a los puntajes del examen estandarizado SAT [Scholastic Assessment Test] en EE.UU), y cómo otros estudiantes con características similares (demográficas, socioeconómicas, información familiar) se desempeñaron en sus pruebas de pregrado y en el examen colombiano estandarizado Saber Pro (el cual es similar a los puntajes GRE -Graduate Record Examination- en EE.UU). La información recolectada fue incluida con la elección de carrera, el sistema de recomendación se realizó usando técnicas de Machine Learning y Deep Learning, la curva ROC (Característica Operativa del Receptor) fue computada para cada carrera, y se encontró que el promedio AUC (área bajo la curva ROC) fue 0.86 a pesar de la alta variabilidad entre ellas, adicionalmente, una métrica de negocio fue construida y evaluada.

Palabras Clave: Recomendación de carreras, educación 4.0, pruebas estandarizadas, aprendizaje automático, aprendizaje profundo.

\section{INTRODUCTION}

Nowadays, more than 20 million students worldwide attend more than 10.000 universities and institutions that offer a wide variety of undergraduate programs. Nevertheless, today's higher education system is struggling, especially in Latin America. In 2017, the World Bank published an article regarding the university desertion rate in Latin America ${ }^{2}$, showing that at least half of undergraduate students complete their careers (at the estimated time) successfully. Colombia's dropout rate has increased by $37 \%$ over the last couple of years, becoming the second country in Latin America with the highest dropout rate right after Bolivia ${ }^{(2)}$. Different factors may have 
contributed to this rapid increase, such as new students' characteristics and the regulation of academic institutions.

This study has considered, as mentioned in the World Bank article, that this high dropout rate correlates, firstly, to the students' lack of academic preparation due mainly to the low-quality education they receive in high school. Secondly, to the shortage of financial means among lowincome students. Thirdly, to the long duration of undergraduate programs, and fourthly, to the academic institutions' strict regulations concerning career change ${ }^{(2)}$.

Recommendation systems are of great importance in decision making. The creation of this model provides the user with a set of options with the hope of meeting expectations. Based on the information used and the algorithms employed to generate recommendations, different techniques can be distinguished such as collaborative filtering, which uses user ratings to recommend items to a specific user by considering other users' preferences to generate new recommendations. Another method relates to specificity-in-content, in which the system displays a set of recommendations based on a characteristic profile from a multiple-user network (3).

Selecting a future career is a complex decision process that involves preferences, skills, interests, and qualities. Current processes, based solely on multi-criteria decision models, allow the handling of only a limited number of options (university degrees). Recommendation models are more suitable due to their relative ease in considering profiles and user expectations. Despite the high impact and usefulness of recommending a college degree, there are several limitations associated with current models that are primarily based on collaboration, filtering, or data mining (including association rules and decision trees). However, the lack of historical information usually makes their use virtually impossible ${ }^{(4)}$.

The purpose of this research is to help tertiary students choose an academic program based on rationality. This is extremely relevant, as their future jobs and possible career opportunities, along with their livelihood, might depend on it. The proposal encompasses the construction of a model based on historical data collected from scores that high-school students have obtained after taking ICFES (Colombian Institute for the Promotion of Higher Education) tests. The structure and relationship with the data are analyzed in order to facilitate the creation of a system that can essentially recommend a plan that would provide high-school students an academically oriented route. This research expects to guide students in the identification of undergraduate programs that accurately match their skills at the beginning of their academic careers in order to potentially reduce dropout rates, increase student satisfaction, and improve their overall experience at the university. 
The study will be presented as follows: first we will go through an overview of previous works on career recommendation prediction, then explore some details about the materials and methods used. Evaluation and modeling are discussed in results. Finally, conclusions and future work will be discussed presented.

\section{RELATED WORK}

Several models have been proposed to solve the career recommendation problem: C. Vialardi et al. wrote an article that utilizes different analyses and data extraction techniques that can be employed while training the recommendation system to work properly ${ }^{(4)}$. It aims to help students, parents, and educators find fitting and appropriate engineering universities according to their profiles and preferences. Recommendation systems reach their objective by displaying the most favorable choice found within large sets of information and volumes of data. Recommendation systems can obtain data by making use of forecasting techniques.

One of the most widely used techniques in data science nowadays are data mining and machine learning, which have increased in popularity due to their effectiveness presenting the required information and filtering the data according to certain criteria and patterns ${ }^{(5)}$. Vialardi, Bravo, Shafti, and Ortigosa conducted a study which outlines different data mining techniques that can be useful to extract the necessary information efficiently ${ }^{(6)}$. This document addresses the problem faced by university students in deciding which courses to take. A similar problem arises when selecting a university. This research proposes data cleaning techniques to perform data pre-processing, and ML algorithms to pattern extraction (models' creation) and defined metrics for evaluation.

Another interesting related work proposes the use of the decision tree approach as the basis for student course selection ${ }^{(7)}$. Different data mining schemes can be used in the education system's business intelligence process to improve efficiency. Decision trees can also assist students in selecting the university to study, based on various criteria that should be specified by the student himself ${ }^{(7)}$. The articles present a recommendation system based on Bayesian inference for online social networks. This allows users to share their content ratings with their friends. Ratings between friends are measured, and a set of probabilities based on mutual ratings derives. When a user launches a query for a particular content rating, a Bayesian network is developed, and a rating is generated for its direct and indirect friends. Similarly, this technique can be employed to obtain highly qualified recommendations for college courses. Ratings from different peers would be considered, and recommendations would be provided based on their network. 
Many students have enrolled in courses without receiving any advice from relevant authorities or university services. Most of them drop out because they do not feel qualified to perform adequately in the undergraduate program they have already chosen. Researchers count aptitudes, personal interests, abilities of the students, and the course itself among the most common causes of the problem. These can lead to low retention rates and education-related failures. In order to improve and support academic management processes, many institutes have started to develop innovative information systems and services with the aim of improving efficiency and student relations. Some of these initiatives present themselves in the form of a Student Referral System (SRM).

This research performs differently from previous work since it is redirected and built for a national government in particular (Colombia), and also due to the fact that there are no previous projects that make use of the scores from national standardized tests, making this a new approach that's only now being explored.

\section{MATERIALS AND METHODS}

\section{Methodology}

The Cross-Industry Standard Process for Data Mining (CRISP-DM) is an open standard process model that describes conventional approaches for data analysis. Also known as one of the most widely used analytics models ${ }^{(8)}$, its structure benefits repeatable processes and large studies. It is important to highlight that CRISP-DM breaks the data mining process into six main phases: business understanding, data understanding, data preparation, modeling, deployment, and evaluation. In the present study, the previously mentioned methodology was applied as follows:

\section{Business Understanding}

At the beginning of the 80s, the Colombian government established a regulatory framework delimited to Colombian Government Standardized Tests as part of the upper-education reform provided by decrees 80 and 81 issued in $1980^{(9)}$. Since then, these academic tests have adopted the form of official, national-wide, and mandatory exams. Thus, becoming a pre-requisite for all high school graduates that desire to enter into the higher education system. This test ("Saber 11 ") is similar to the SAT (Scholastic Assessment Test) in the United States. Later on, with decree 1781 issued in 2003, the Colombian government established another test as mandatory (ECAES -currently known as "Saber Pro"-). It covers all undergraduate students and measures and evaluates quality in higher education ${ }^{(10)}$. This test can be compared to both the GRE (Graduate 
Record Examination) and the GMAT (Graduate Management Admission Test) in the United States and comprises a requisite for undergraduates in Colombia to obtain their degree.

The Colombian government has made public the data of all the individuals that have taken both tests. The data remains anonymized, but it includes an ID that allows one to match the results from "Saber 11 " and "Saber Pro" when a person has already taken both. In addition to test results, the data also includes demographic information. Plenty of analysis has been performed already to find out who is the best high-school graduate, which university has the best average score, and which program is better by comparing it at different universities. However, the individually-based data has not been used much, so far, to develop a recommendation system for career choices or to find out if the performance on the Saber 11 test has an impact on undergraduate degree choice.

\section{Data Understanding}

The Colombian Institute of Education provides access to a Microsoft OneDrive repository that hosts datasets that collect state-regulated assessments. In this study, the following datasets were analyzed:

Table 1. Collected datasets from the Colombian Institute of Education

\begin{tabular}{|c|c|}
\hline Dataset & Time \\
\hline Saber 11 test results & 2006 to 2014 \\
\hline Saber Pro test results & 2012 to 2018 \\
\hline
\end{tabular}

Source: Own elaboration

There are 740.399 student records, including both tests (Saber 11 and Saber Pro). Years 2008 to 2014 were chosen since data records in this period share almost the same data structure, making it possible to merge them correctly.

The Saber Pro test includes a set of domain-specific questions such as finance, engineering, and science, and an assortment of generic questions for all academic disciplines that include English and citizenship skills.

High school students that graduate in June have significantly higher test scores than those graduating in December. In particular, in the northern region of the country, English tests score are considerably higher than in other regions. Likewise, the score's mean is statistically higher for some population groups than others, for instance, when comparing income brackets. 


\section{Data Preparation}

While analyzing the datasets, some meaningful period-related differences were found. It was then necessary to select a subset of Saber 11 data to match the score scaling and grading system over the analyzed years. Database variables were grouped into eight-band groups, referring to the following data topics: personal, contacts, socioeconomic, education background, expectations, school information, test structure, and scores. After analyzing missing values and relevant features, forty-eight variables were removed from the Saber 11 dataset and thirty-five from the Saber Pro dataset.

Data from both tests (Saber 11 and Saber Pro) have categorical variables, including socioeconomic features such as gender, parent's income (as income intervals), city of origin, number of books at home, among many others. These categorical variables were converted into dummy variables to analyze the correlation between these and the test scores. It was also found that socioeconomic variables with the highest correlation to the scores and career choice are biased: gender, city of origin, and parent's income.

Regarding the diverse dataset structures in this study, the previously mentioned variables were not used due to the merging process between Saber 11 and Saber Pro. In order to compare scores among periods and tests, scores were standardized with respect to the mean and standard deviation of each period.

\section{RESULTS}

\section{Modeling}

The chosen machine learning algorithms for multiclass classification ( 54 classes) problem used were neural networks, random forest, and logistic regressions, which were built to predict the compatibility to a particular career given a student's high school test scores. An eight-feature input was defined where each one of them represents the score the student got in each subject the Saber 11 test evaluates. Involved knowledge areas are Math, English, Language, Biology, Social Sciences, Philosophy, Chemistry, and Physics with such knowledge areas we predict the probability that they will study and finish a career.

Explain that this is multiclass classification problem with 7 predictors and 70 classes.

\begin{tabular}{|c|c|}
\hline Model & Parameters \\
\hline & Max Depth : 12 \\
\hline
\end{tabular}




\begin{tabular}{|c|c|}
\hline Random Forest & Class Weight : Balanced \\
& Random State : 10 \\
\hline Neural Network & Layers : [1024, $512,512,79]$ \\
\hline Logistic Regression & Solver : Igbfs (Limited-memory Broyden- \\
Fletcher-Goldfarb-Shanno.) \\
Tot (Tolerance for stopping criteria) : $1 \mathrm{e}-4$ \\
fit_intercept : True \\
Multiclass : multinomial \\
Max_iter : 500 \\
\hline
\end{tabular}

Source: Own elaboration

Careers with less than 400 students in the whole country were removed from the merged dataset, filtering the career count from 1.400 to 54 . Each classification model aimed to predict the compatibility ratio for only 54 careers.

For the modeling approach, different models were tested in order to identify how well each one performed, selecting then, the one with better results. In addition, to train each model, a classbalancing procedure was applied using the oversampling approach, hyperparameter tuning, and a grid search method that led to the previous parameters on the models. Finally, cross-validation (CV) with k-fold was used, with $k=5$, and with a CV splitter which splits the dataset into a sequence of train and test portions scheme, this, to assess the generalization for each model.

\section{Evaluation}

A measure called Top 5 was included, besides of accuracy and AUC. The top 5 metric establishes whether a career is compatible with a student in case the model predicts the career among the top 5 with the highest probabilities, this because was necessary to define a business metrics based on the context of this project. On the other hand, the area under the ROC curve, also known as AUC, is a measure of the probability that a correct prediction for a given category will be made. This measure is achieved by calculating the area under a curve created when graphing true positive rates against that of false positives for multiple decision thresholds ${ }^{(11)}$.

Table 2. Metrics of classification models

\begin{tabular}{|c|c|c|c|}
\hline Metric & Neural Network & Random Forest & Logistic Regression \\
\hline Accuracy & $13 \%$ & $4 \%$ & $13 \%$ \\
\hline
\end{tabular}




\begin{tabular}{|c|c|c|c|}
\hline Top 5 & $60 \%$ & $19 \%$ & $20 \%$ \\
\hline AUC & $86 \%$ & $77 \%$ & $58 \%$ \\
\hline
\end{tabular}

Source: Own elaboration

A relation between the AUC results and the amount of data per career was found. In Figure 1 you may find the AUC scores and the frequencies with which every career appears in the dataset. In order to fit the frequencies with the AUC scores on the same scale, the overall number of instances of each career was divided by the most frequent career number of instances. The data was plotted in a way that the AUC scores are sorted ascendingly. The graphs clearly show a descending tendency regarding the number of instances that the career possesses, demonstrating that an inverse relationship exists between the frequency of the class and how accurately the model is capable of predicting such class, also to mention that as they are 54 classes, assuming that all of them have equal probability to occur because of undersampling, the model would have an accuracy of $1.86 \%$ if were random so accuracy also has a good score.

Source: Own elaboration

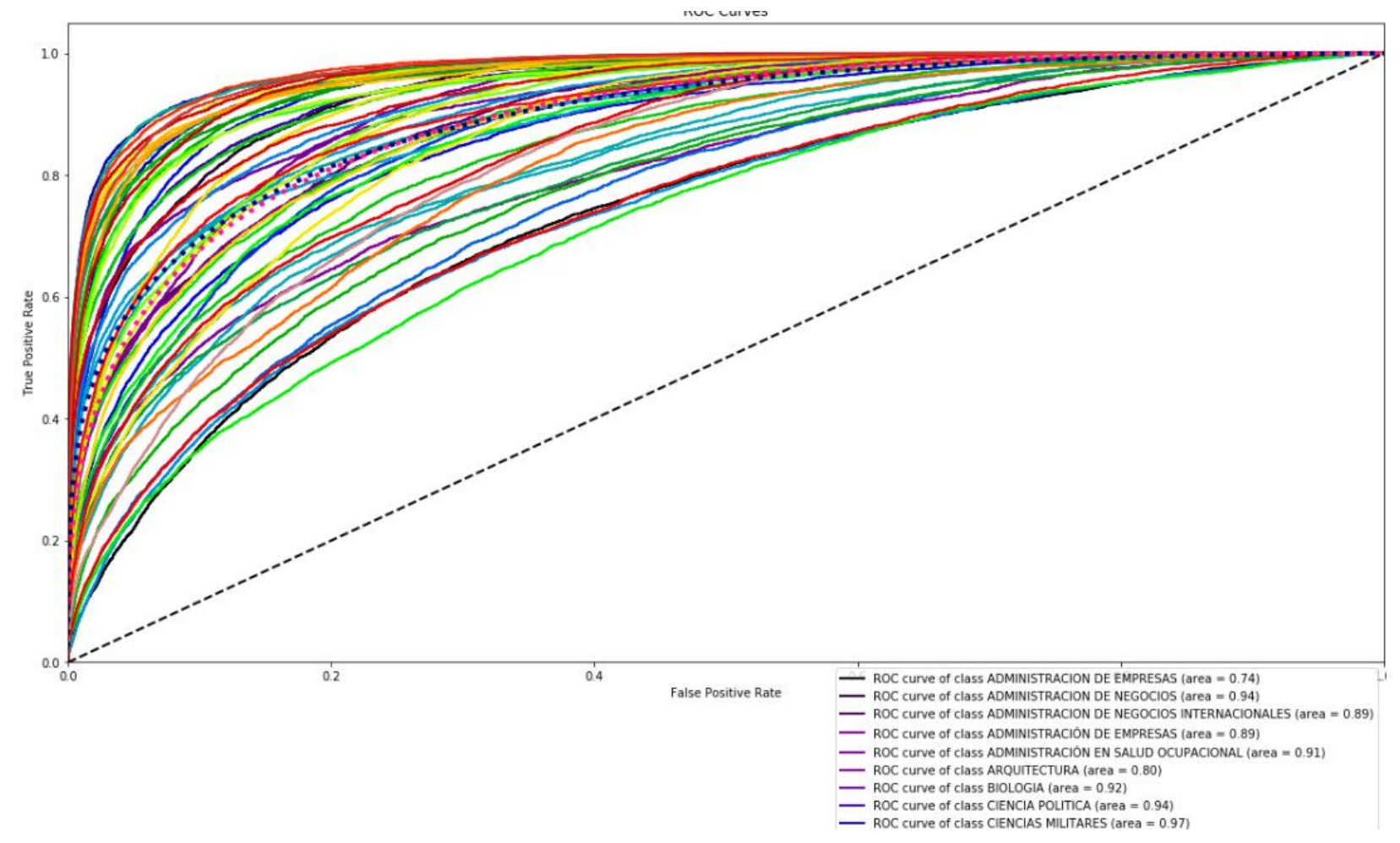

Figure 1. ROC Curves per career (Neural Networks) 
Source: Own elaboration

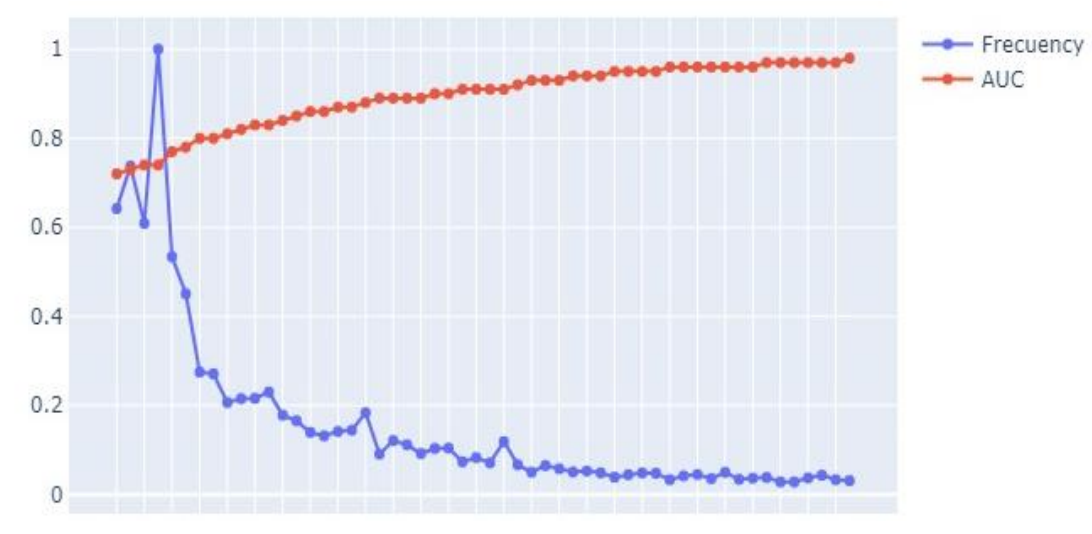

Figure 2. Percentage of data and AUC score, each point is a career.

It was found that the model that works with Neural Networks predicted with higher accuracy the classes that possessed lower quantities of data. The model worked with a small sample of the available data for the careers who held greater amounts of instances and those who presented lower amounts of data were predicted with more precision not only because the model worked with a greater sample of the available data, but because such careers often possess lower amounts of students in real life as well. Since fewer people study such careers it is easier to identify the relations and the characteristics that may lead to the prediction in the scope of our study. Consequently, performing such a task is harder on more crowded careers since relations and characteristics are likely to only be generally recognized.

\section{Deployment}

Figure 2 shows a Dashboard developed with node-js and their respective python backend. In this dashboard, students will be asked to type their SABER 11 test scores, and the model will deploy their compatibility with a set of different careers, according to the results of student that previously studied such career, showing them, in a respective decreasing probability order, in general, the career affinity score (or probability to choose it) depends on the scores entered by the student. 


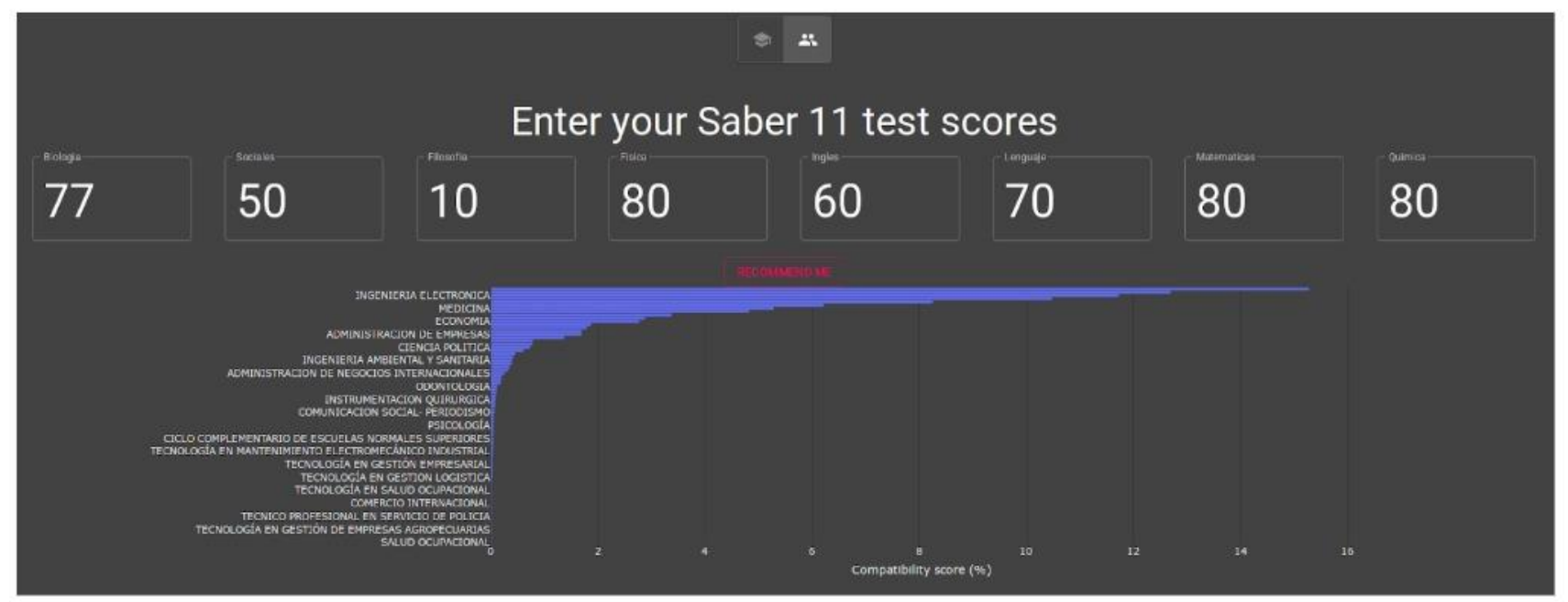

Figure 2. Dashboard of the career recommendation system.

\section{CONCLUSIONS AND FUTURE WORK}

In this work, it's become apparent that predicting which career path a student will take based solely on Saber 11 and Saber Pro test scores is such a complex task that the creation of new metrics was needed. This process requires insight from the data, combined with different $\mathrm{ML}$ approaches. For this purpose, three different algorithms were tested, of which only the one with a higher AUC was selected, along with a personalized metric score.

Colombia should include a vocational test in both exams, such as the 16PF (16 personality factors) built by Raymond B. Cattell (9), which is a self-report personality test, in order to better understand the vocational preferences of students, thus allowing for better recommendation systems, like the one discussed in this study, to be built and improved from here on out.

Some variables were intentionally excluded from the model due to them representing a risk of biased decision making which could have resulted in discrimination or other unwanted side effects. Some of these variables were income level, parent's professional degree, and geographic location.

As for future work, the addition of analytic tools on the dashboard has been considered a useful feature which could allow policymakers to make more informed and equative decisions when comparing the performance of all students nationally, in order to improve the quality of 
education while tending to issues related to socioeconomic inequality which may steem from current the current state of affairs.

\section{REFERENCIAS}

[1] F. Woolley. "Why it's so hard to measure a 'quality' education". The Globe and Mail. 2012. Accessed on: Jun 26. 2020. URL: https://www.theglobeandmail.com/report-onbusiness/economy/economy-lab/why-its-so-hard-to-measure-a-qualityeducation/article542509/

[2] M. M. Ferreyra, C. Avitabile, J. Botero, F. Haimovich y S. Urzúa. "Momento decisivo. La educación superior en América Latina y el Caribe". Grupo Banco Mundial. 2017. Accessed on: Nov. 19, $2019 . \quad$ URL: https://openknowledge.worldbank.org/bitstream/handle/10986/26489/211014ovSP.pdf

[3] M. R. Maridueña and A. Febles. "A college degree recommendation model". DYNA. Vol. $83 \mathrm{~N}^{\circ}$ 199, pp.29-34. 2016. DOI: 10.15446/dyna.v83n199.54360.

[4]_A. H. Ragab, A. F. Mashat, and A. Khedra. "HRSPCA: Hybrid Recommender System for Predicting College Admssion". International Conference on Intelligent Systems Design and Applications (ISDA). DOI: 10.1109/isda.2012.6416521.

[5] L. Deshpande, N. Dikhale, H. Srivastava, A. Dudhane, U. Gholap. "College recommendation system". International Research Journal of Engineering and Technology Vol. N3 2020.

[6] C. Vialardi, J. Bravo, L. Shafti, A. Ortigosa. "Recommendation in Higher Education Using Data Mining Techniques". Paper presented at the International Conference on Educational Data Mining 2009.

[7] D. Lakshmi, S. Arundathi, D. Jagadeesh. “Data Mining: A prediction for Student's Performance Using Decision Tree ID3 Method". International Journal of Scientific \& Engineering Research, Vol. 5,2014

[8] R. Wirth, J. Hipp. “CRISP-DM: Towards a Standard Process Model for Data Mining”, 1-11. 2000. 6/28/2020. URL: http://www.cs.unibo.it/ danilo.montesi/CBD/Beatriz/10.1.1.198.5133.pdf.

[9] Ministerio de Educación Gobierno de Colombia. “Decreto 2343 de Septiembre 4 de 1980". Accessed on: Jun. 01, 2020. URL: https://www.mineducacion.gov.co/portal/ejestematicos/Normas-sobre-Educacion-Preescolar-Basica-y-Media/103244:Decreto-2343-de-

Septiembre-4-de-1980

[10] Asociación Colombiana de Facultades de Ciencias. "Pruebas ECAES Saber Pro". Accessed on: Jun. 01, 2020. URL: http://www.acofacien.org/index.php/biblioteca/pruebas-saber

[11] T. Fawcett. "An introduction to ROC analysis". Pattern recognition letters, vol. 27, N 8, pp. 861-874. 2006. DOI: 10.1016/j.patrec.2005.10.010 